\title{
Evaluate the Performance and Emission using EGR (Exhaust gas recirculation) in Compression-ignition engine fuelled with blend.
}

\author{
Hardik B. Charola ${ }^{1}$, C. D. Sankhavara ${ }^{2}$, M.B.Charola ${ }^{3}$ \\ ${ }^{I} P G$ Student, R K University, Rajkot, Gujarat, INDIA. \\ ${ }^{2}$ Dean - Faculty of technology, $R$ K University, Rajkot, Gujarat, INDIA \\ ${ }^{3}$ Asst. Prof, LTIET Engineering College, Rajkot, Gujarat, INDIA
}

\begin{abstract}
To study different paper related to exhaust gas recirculation on four stroke compression ignition engine fuelled with diesel/methanol blend of 10:90, 20:80 and 30:70 of methanol to diesel respectively were studied to evaluate the performance and emission of engine. The performance of diesel engine increase with increase in compression ratio exhaust gas recirculation is a common way to control in-cylinder NOx production and is used in most modern high speed direct injection diesel engines because it lowers oxygen concentration and flame temperature of the working fluid in the combustion chamber. To study evaluate and performance with different EGR rate with and without variable compression ratio. After studying all different papers to review the result the output power and torque for diesel fuel is lower compared to methanol-diesel blended fuel at any mixing ratio and because of EGR the $N_{x}$ emission and exhaust gas temperature reduced but emissions of particulate matter (PM), HC, and CO were found to have increased with usage of EGR in CI engine.
\end{abstract}

Keyword: CI engine, EGR, methanol blend, exhaust emission, engine performance.

\section{Introduction}

It can be obviously seen that the world's fossil fuel reserves are limited. It is well known that passenger vehicles are dependent on fossil fuels such as gasoline, diesel fuel, liquefied petroleum gas, and natural gas. The fossil fuel used in passenger vehicles induces the air pollution, acid rains; build-up of carbon dioxide petroleum product will become very scarce and costly etc [1]. Another reason motivating the developing of alternative fuels for the IC engine is concern over the emission problems of Diesel engine. Hence, there is a progressively interest related with using non-fossil sources in vehicles. Especially, the alcohol fuels (methanol, ethanol etc.) have been showed good candidates as alternative fuels for the vehicles equipped with CI (compression ignition) engines. Methanol is an attractive alternative fuel because they can be obtained from both nature and manufactured sources. It is a high octane fuel with anti-knock index number and also in methanol has low sulphur content in the fuel. Methanol can be used in blends with diesel based engine fuels. The smaller the methanol percentage addition, the easier typical blending problems of phase separation, corrosion, changed Vapour pressure; changed air requirement can be solved[]compression-ignition engine with methanol was reported that performance improved and exhaust emissions reduced with methanol operation. Carbon monoxide (CO) and un-burnt hydrocarbons (UBHC), major exhaust emissions formed due to incomplete combustion of fuel, cause many human health disorders. [3] The friction and wear in automobile components to increase both fuel consumption \& emission and reduce engine power, it was reported the frictional loss was increase about $25 \%$ of the overall fuel consumption in engine. The ratio of $\mathrm{NO} 2$ and NO in diesel engine exhaust is quite small, but NO gets quickly oxidized in the environment, forming NO2 [4]. Since diesel engine mainly emits $\mathrm{NO}$ hence attention has been given to reduce the NO formation [5].

\section{Performance And Emission Analysis Of Using Methanol:}

Najafi[3] in four stroke four cylinder direct injection diesel engine used certain mixing ratio of 10:90, 20:80 and 30:70 of methanol to diesel respectively the Experimental results showed that the output power and torque for tested diesel fuel was lower compared to methanol-diesel blended fuel at any mixing ratio. The best mixing ratio that produced the lowest exhaust temperature was at 10\% of Methanol in $90 \%$ of Diesel fuel.

Suresh et al. [28] modified a single cylinder vertical air cooled diesel engine to use methanol dual fuel mode and to study the performance, emission, and combustion characteristics. The primary fuel, methanol with air, compressed, and ignited by a small pilot spray of diesel. Dual fuel engine showed a reduction in oxides of Nitrogen and smoke in the entire load range. However, it suffers from the problem of poor brake thermal efficiency and high hydrocarbon and carbon monoxide emissions, particularly at lower loads due to poor ignition. In order to improve the performance at lower loads, a glow plug was introduced inside the combustion chamber. The brake thermal efficiency improved by $3 \%$ in the glow plug assisted dual fuel mode, especially at low load, and also reduced the hydrocarbon, carbon monoxide, and smoke emissions by $69 \%, 50 \%$ \& $9 \%$ respectively. The presence of glow plug had no effect on oxides of nitrogen. 
Turkcan et al.[5] studied the influence of methanol/diesel and ethanol/diesel fuel blends on the combustion characteristic of an IDI diesel engine at different injection timings by using five different fuel blends (diesel, $\mathrm{M} 5, \mathrm{M} 10, \mathrm{E} 5$ and E10). The tests were conducted at three different start of injection $\left\{25^{\circ}, 20^{\circ}\right.$ (original injection timing) and $15^{\circ} \mathrm{CA}$ before top dead center (BTDC) \} under the same operating condition. The experimental results showed that maximum cylinder gas pressure (Pmax) and maximum heat release rate $(\mathrm{dQ} / \mathrm{d} \theta)$ max increased with advanced fuel delivery timing for all test fuels. Although the values of Pmax and $(\mathrm{dQ} / \mathrm{d} \theta) \max$ of E10 and M10 type fuels were observed at original injection and retarded injection (15 CA BTDC) timings,

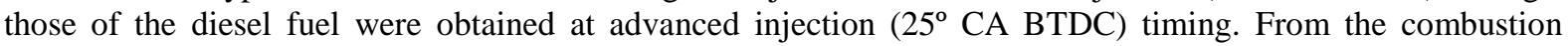
characteristics of the test fuels, it was observed that ignition delay (ID), total combustion duration (TCD) and maximum pressure rise rate $(\mathrm{dP} / \mathrm{d} \theta)$ max increased with advanced fuel delivery timing. The ID increased at original and advanced injection timings for ethanol/diesel and methanol/diesel fuel blends when compared to the diesel fuel.

Zhiqiang Guo et al. [15] in this research paper to conduct experiment test on a single cylinder 4-stroke water-cooled direct injection diesel engine. The coolant temperature of water jacket was kept at $75^{\circ} \mathrm{C}$ during the experiments, and exhaust gas like NOx, CO, HC, PM were measured by exhaust gas analyser. Effects of different blend containing different proportions on engine combustion and emissions. Take reading pure diesel and the blends of diesel with $10 \%, 20 \%$ and $30 \%$ by volume were investigated.

Z.H. Zhang [16] The test engine is a 4-cylinder water cooled direct-injection diesel engine. The engine was coupled with an eddy current dynamometer to measure performance and the engine speed and torque were controlled by the Ono Sokki diesel engine test system. Regulated emissions including HC, NOx, and CO were measured using online exhaust gas analysers. Experiments were carried with the diesel fuel taking up $80 \%$ and $70 \%$ of the desired engine load, with bland fumigation methanol providing $20 \%$ and $30 \%$ of the desired engine loads.

Chunde Yao [6] This paper introduces Diesel/methanol compound combustion system (DMCC) and its application to a naturally aspirated Diesel engine with and without an oxidation catalytic converter the experiment was carried out on 4 stroke 4 cylinder diesel engine. The differences in the physical and chemical properties of methanol and Diesel fuels, as well as the stage of combustion, result in the changes in the heat release flow pattern. Methanol results in a rapid release of heat energy. The experimental results shows that the Diesel engine operating with the DMCC method could simultaneously reduce the soot and coupled with an oxidation catalyst, the $\mathrm{CO}, \mathrm{HC}, \mathrm{NOx}$ and could all be reduced.

Huang et al. [17] who investigated in combustion of Diesel blended with methanol in single cylinder water cooled diesel engine. They also found that the methanol blended diesel caused an increase in ignition delay period, peak heat release rate of combustion and the premixed heat release but a shortening of the diffusion combustion duration. Thus, the effects of methanol on the combustion characteristics are the same whether the methanol the cylinder temperature of the diesel bland with methanol engine is lower than that of the baseline Diesel engine.

Yaopeng Li [7] A mechanism was applied to investigate the combustion and emission characteristics of a methanol/diesel reactivity controlled compression ignition (RCCI) engine. The fuel was supplied separately by directly injecting diesel fuel into cylinder well before top dead centre, while premixing methanol through the intake port in the tested methanol/diesel RCCI engine. The experimental results show that increasing methanol fraction and advancing the SOI are beneficial to improve fuel economy and avoid engine knock and slight increase in NOx due to the higher burning temperature.

Cenk Sayin[8] The effect of injection timing on the exhaust emissions of a single cylinder, naturally aspirated, four-stroke, DI diesel engine has been experimentally investigated by using methanol-blended diesel fuel from $0 \%$ to $15 \%$ with an increment of $5 \%$. The tests were conducted for three different injection timings $\left(15^{\circ}, 20^{\circ}\right.$ and $25^{\circ} \mathrm{CA}$ BTDC) at four different engine loads $(5 \mathrm{Nm}, 10 \mathrm{Nm}, 15 \mathrm{Nm}, 20 \mathrm{Nm})$ at $2200 \mathrm{rpm}$. The experimental results shows that the NOx and $\mathrm{CO} 2$ emissions increased as BTE, smoke opacity, $\mathrm{CO}$ and UHC emissions decreased with increasing amount of methanol in the fuel mixture. With the advanced injection timing (25 CA BTDC) we can get the best result.

Zuohua Huang [18] in this paper to study cylinder pressure analysis was conducted in a compression ignition engine. To increasing methanol mass fraction of the diesel/methanol blends would increase the heat release rate in the burning in combustion chabar and shorten the combustion duration of the diffusive burning phase. The ignition delay increased with the advancing of the fuel delivery advance angle for both the diesel fuel and the diesel/methanol blends. The maximum mean gas temperature remained almost near about to diesel fuel, a slight increase with the advancing of the fuel delivery advance angle, and it only slightly increased for the diesel/methanol blends compared to that of the diesel fuel. To increase a cylinder gas pressure increased with the advancing of the fuel delivery advance angle.

Z H Huang [1] a study on the performance and emissions of the diesel-methanol blend was carried out in a single cylinder compression ignition engine. The experimental results shows that a marked reduction in the 
exhaust $\mathrm{CO}$ and smoke can be achieved when operating with the diesel-methanol blend and NOx increases with increase in the mass of methanol added also methanol addition to diesel fuel was found to have a strong influence on the NOx concentration at high engine loads rather than at low engine loads.

P. C. Jikar [4] A four stroke four cylinder diesel engine was tested using methanol blended with diesel at certain mixing ratio of 10:90, 20:80 and 30:70 of methanol to diesel respectively. The experimental results shows that the specific fuel consumption for diesel alone was higher compared to any mixing ratio. It was noticed that brake thermal efficiency was thus improved in almost all operation conditions with the methanol and diesel blended fuels the amount of No is increased.

M.H. Mat Yasin [19] the focus on this study paper is to evaluate the performance and emissions of a small proportion of methanol (5\% by volume) in a blend and mineral diesel separately. A compression ignition (CI) Mitsubishi 4D68 multi-cylinder DI diesel engine was used for measure performance and emission in this work. Engine performance, combustion and exhaust emission characteristics were evaluated at two different engine speeds from $1500 \mathrm{rpm}$ to $3500 \mathrm{rpm}$ at partial engine load. Lower brake power was noticed when operating with M5 blend. However, an increase in brake specific fuel consumption (BSFC) of $4 \%$ to $6 \%$ was observed when the engine was fuelled with methanol 5\% blend. The results indicate that NOx emissions increase up to $13 \%$ and while lower carbon monoxide (CO) and Carbon dioxide (CO2) up to $17 \%$ to $18 \%$ are observed in compare with the mineral diesel.

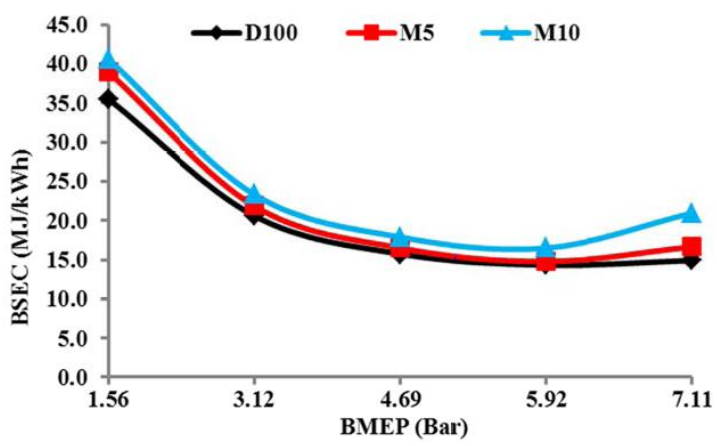

Fig 1 Brake Specific Fuel Consumption v/s Mean Effective Pressure [2]

C. Mishra [2] in this project the test fuels were prepared with $5 \%$ and $10 \%(\mathrm{v} / \mathrm{v})$ of methanol in the emulsion and experiments were conducted on a single cylinder diesel engine. The experimental results shows that emission of $\mathrm{CO}$ was found to reduce at all loads with increase in methanol composition in test fuel also M5 and M10 produced less Nox emission at part load than diesel base line however at full load M5 and M10 produced more Nox emission than diesel base line.

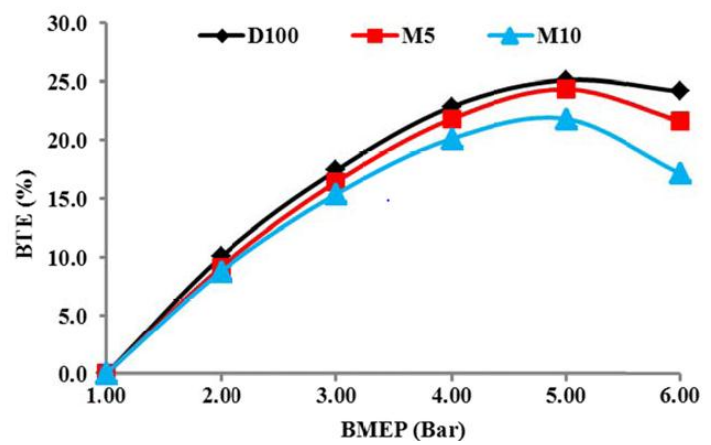

Fig 2 Brake Thermal Efficiency v/s Mean Effective Pressure [2]

\section{Performance And Emission Analysis Of Using Egr:}

Jaffar Hussain [10] the experiment was carried out on four-stroke 3 cylinder air cooled CI engine with $0 \%$ to increment of $5 \%$ up to $25 \%$ of EGR recirculation. The experimental results show that the emission of Nox was decreased because it lowers the oxygen concentration and flame temperature. The emission of $\mathrm{HC}, \mathrm{CO}$, and PM was increased. The thermal efficiency is slightly increased and BSFC is decreased at lower load.

D.T. Hountalas [20] in the present paper it is examined, using a heavy duty DI single cylinder diesel test engine capable of operating at high peak combustion pressures. Also to advanced injection timing was used to improve its brake specific fuel consumption (bsfc) that obviously had a negative impact on NO $\mathrm{x}$ emissions. To control NOx , cooled EGR was considered using a fixed temperature for all test cases examined. In the present work are examined various EGR temperatures to determine its effect on the combustion and pollutant formation. The increase of EGR percentage results to a decrease of NO and to a sharp increase of soot. The effect on both pollutants is stronger at low engine speed. The maximum estimated reduction of brake thermal 
efficiency is in the order of 5.5\% relative to the value without EGR, observed at $15 \%$ EGR for an engine speed of $1130 \mathrm{rpm}$.

M. Ghazikhani [11] The experiment was conducted on the 4 stroke 4 cylinder water cooled CI engine with $0 \%$ to increment of 5\% up to $30 \%$ to study the chemical and thermal effect The experimental results shows that at $25 \%$ of load the BSFC was decreased with the increase amount of EGR and as the equivalence ratios go up, the irreversibility is also increased.

Giorgio Zamboni [12] the experiment was conducted on the 4 stroke 4 cylinder water automotive diesel engine with two different circuits HP circuit and LP circuit. The experimental results shows that for the same rate of EGR HP circuit gives better result compare to LP circuit in Nox emission.

Giorgio Zamboni [13] investigation was performed with a view to comparing high and low pressure exhaust gas recirculation systems (HP and LP EGR) fitted on an automotive turbo charged diesel engine, focusing on analysing their influence on fuel consumption, pollutant emissions and the combustion process. Parameters were measured in six part-load operating conditions related to the European driving cycles. The investigation performed, the most substantial reductions in NOx were obtained through the joint application of both the EGR circuits with the highest HP EGR valve opening setting. It is confirmed that the impact of the LP EGR circuit on intake and exhaust parameters like mass flow rate, temperature and pressure levels is lower than that of the HP EGR loop, resulting in engine and turbocharger working conditions closer to the without EGR. As HP EGR is associated with significant reductions in this gradient, lower bsfc values are usually observed.

Federico Millo [21] to evaluated by means of both experimental tests and numerical simulation in addition to the experimental tests, a one-dimensional fluid-dynamic engine model has been built in order to assess the potential of a Dual Moad (DM) EGR system a combination of Short Route (SR) and Long Route (LR) EGR systems. Substantial reductions of the NOx emissions have been achieved using the LR EGR layout both under steady state and transient operating conditions a reduction. The use of a Long Moad EGR system has resulted to be extremely effective in reducing NOx emissions reduction, both under steady state and transient operating conditions a reduction of up to $15 \%$ in comparison with the conventional Short Moad system.

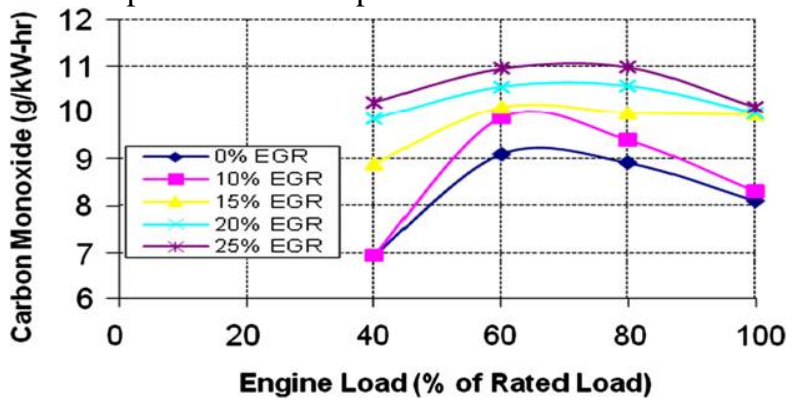

Fig 3 Carbon Monoxide v/s Engine Load [9]

N. Ravi Kumar, [9] the experiment was conducted on single cylinder direct injection variable compression high speed diesel engine with 0\%, 5\% and 10\% EGR. The experimental results show that with increase in compression ratio the brake thermal efficiency increases and specific fuel consumption decreases. It was observed that with raise in \% of EGR the percentage increase in brake thermal was up to $13.5 \%$. It was found that with raise in \% EGR the NOx emissions was gradually decreases by $11 \%$ to $85 \%$ at different compression ratios due to less flame temperatures and low oxygen content in the combustion chamber. Smoke opacity is also decrease.

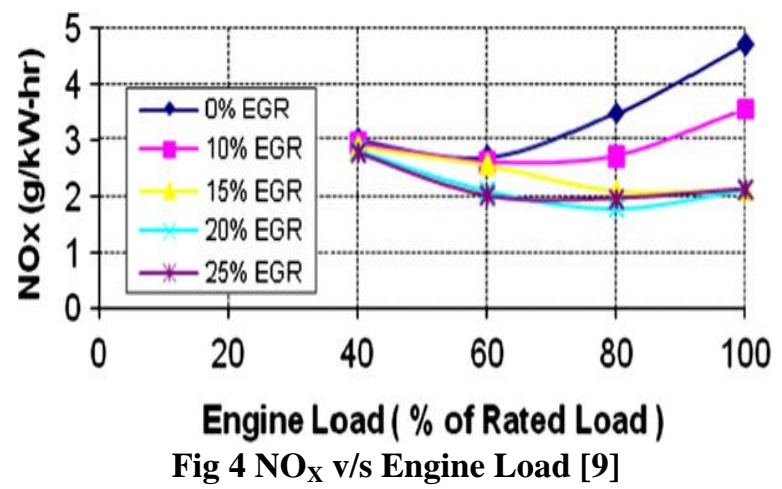

Deepak Agarwal, [13] the experiment was conducted on the two cylinder 4 stroke constant speed diesel engine for varying \% of EGR from 0 to $20 \%$ in the increment of $5 \%$. The experimental results show that the thermal efficiency increases at lower loads. The volumetric efficiency is decreased. The HC and CO emission increase with increase of EGR and the degree of reduction of Nox is higher at higher loads. Higher soot deposits were 
observed on cylinder head, injector tip, and piston crown of EGR operated engine than without EGR operated engine.

Avinash Kumar Agrawal, [14] the experiment was conducted on the two cylinder 4 stroke air cooled diesel engine for varying $\%$ of EGR from 0 to $21 \%$ in the increment of $3 \%$. The experimental results shows that the PM emission in the exhaust is increase the thermal efficiency and BSFC in not affected significantly and EGR is proved to be one of the most efficient methods of NOx reduction in diesel engines.

Ming Zheng, [22] it has been argued whether EGR should be applied to Diesel engines because of the increased piston-cylinder wearing. Heavy uses of EGR could also deteriorate the energy efficiency, operational stability and PM generation of the engine. The current concern is on how aggressively EGR should be applied to all speeds and all loads; although EGR increased wearing continues to be problem affecting engine durability and performances. EGR is still the most viable technique that can reduce NO x dramatically. Energy efficient after treatment systems dealing with NOx and PM simultaneously are still in the early development stages. The inability of available catalytic after treatment technologies further encourages aggressive uses of EGR.

Jaffar Hussain et al. [10] the experiment was carried out on 4 stroke 3 cylinder air cooled CI engine with $0 \%$ to increment of $5 \%$ up to $25 \%$. The experimental results show that the emission of Nox was decreased because it lowers the oxygen concentration and flame temperature. The emission of HC, CO, and PM was increased. The thermal efficiency is slightly increased and BSFC is decreased at lower load.

Harilal S. Sorathia [23] Recirculate exhaust gas lower the oxygen concentration in combustion chamber and increase the specific heat of the intake air mixture, which results in lower flame temperatures. It was observed that $15 \%$ EGR rate is found to be effective to reduce NOx emission substantially without deteriorating engine performance in terms of thermal efficiency, bsfc and emissions. Thus, it can be concluded that higher rate of EGR can be applied at lower loads and lower rate of EGR can be applied at higher load. EGR can be applied to diesel engine fuelled with diesel oil, bio-diesel, LPG, hydrogen without sacrificing its efficiency and fuel economy and NOx reduction can thus be achieved.

Murari Mohan Roy et al [24] investigate on EGR and cyclonic separator for simultaneous reduction of NOx and PM in DICI engine under different load and speed. There is reduction of NOx by EGR but increase in PM, and PM is reduced by the use of cyclonic separator. Average NOx reduction at $10 \%$ EGR rate under different loads and speeds is about $24 \%$, but average PM increase is about $12 \%$. NOx is reduced about $47 \%$ at $20 \%$ EGR rate, but PM increase is about $65 \%$. At 30\% EGR rate, NOx reduction is about 77\%, but PM increase is about $156 \%$.

V.Pradeep, R.P.Sharma [25] using with 5\% EGR, the NO level came down to 1105ppm to 900ppm for diesel, at full load. With 10\% EGR, NO levels were 885ppm to 910ppm for diesel. With 15\% EGR, NO levels were found to be 772ppm to 780ppm for diesel at full load. Even though 20 and $20 \%$ EGR were able to reduce NO by a large amount, reduction in BTE and large increase in smoke, CO and HC emissions were observed. Conclude that HOT EGR of $15 \%$ effectively reduced NO emission without much adverse effect on the performance, smoke and other emissions.

H.E.Saleh [26] effect of EGR with jojoba methyl ester on diesel engine is attempted to reduce nitrogen oxide. At high speed, the engine output and efficiency with JME were higher than that with diesel fuel. The NOx concentration with JME fuel is higher than that with diesel fuel. It is difficult to employ an EGR rate larger than $12 \%$, and this may result in an excessive increase in BSFC up to $11 \%$. The reduction in NOx was $33 \%$ at that level of EGR rate. For all operating conditions, a better trade-off between HC, CO and NOx emissions can be attained within a limited EGR rate of 5-15\% with little economy penalty.

V.V.Prathibha Bharathi [27] investigates the effect of EGR with different blend and Grooved Piston with Knurling in an IC engine of single cylinder water cooled. Tests were conducted on 10\%, 15\% and $20 \%$ EGR. There is a gain of $7.4 \%$ with $20 \%$ EGR compared to normal engine. By EGR20 $2.94 \%$ of fuel consumption were observed compared to normal engine. $13 \%, 5.4 \%$ and $2.9 \%$ reduction of $\mathrm{NOx}, \mathrm{HC}$ and $\mathrm{CO}$ were measured. Investigated that combination of different blend with EGR20 and piston with nine grooves give better performance and reduced emissions.

\section{Conclusion}

From all above paper we can conclude that by adding methanol HC, CO emission will decrease while the NOx emission will increase on other side by recirculating the increasing percentage of EGR the NOX emission will be drastically decrease and HC, CO and PPM will increase. As increasing in the compression ratio the blended fuel will give lower brake specific fuel consumption. The work can be enhanced by using different proportion of blended fuel with different EGR rate. 


\section{Acknowledgement}

I am thankful to all the faculty members of Mechanical Engineering Department and my parents and all my friends who helped me in prepare review paper and give direction with their suggestions and their rich experience.

\section{Reference:}

[1] Z H Huang, H B Lu, DM Jiang, K Zeng, B Liu, J Q Zhang and XBWang Engine performance and emissions of a compression ignition engine operating on the diesel-methanol blends Proceedings of the Institution of Mechanical Engineers, Part : Journal of Automobile Engineering 2004 218: 435 DOI: 10.1243/095440704773599944

[2] C. Mishra, N. Kumar, B.S. Chauhan, H.C Lim, M. Padhy Some Experimental Investigation on use of Methanol and Diesel Blends in a Single Cylinder Diesel Engine International Journal of Renewable Energy Technology Research (IJRETR) Vol. 2, No. 1, PP: 01 -16, January 2013, ISSN: 2325-3924 (Online)

[3] Najafi G.Yusaf T.F (2009). Experimental investigation of using methanol-diesel blended fuels in diesel engine. Proceedings of the Fourth International Conference on Thermal Engineering: Theory and Applications January 12- 14, Abu Dhabi, UAE

[4] Jikar P.C.,BawankureM.D., Rokade A.G. performance evaluation of using methanol-diesel blended fuels in CI engine. International Conference on Mechanical, Production and Automobile Engineering (ICMPAE'2011) Pattaya Dec. 2011.

[5] Turkcan A, Canakci M. Combustion Characteristics of an Indirect Injection (IDI) Diesel Engine Fuelled with Ethanol/Diesel and Methanol/Diesel Blends at Different Injection Timings. World renewable energy congress 2011- Sweden, 8-13 May, Linkoping, Sweden on Sustainable Transport

[6] Chunde Yao ,C.S. Cheung, Chuanhui Cheng, Yinshan Wang, T.L. Chan , S.C. Lee Effect of Diesel/methanol compound combustion on Diesel engine combustion and emissions Energy Conversion and Management 49 (2008) 1696-1704

[7] Yaopeng Li, Ming Jia , Yaodong Liu, Maozhao Xie Numerical study on the combustion and emission characteristics of a methanol/diesel reactivity controlled compression ignition (RCCI) engine journal homepage: www.elsevier.com/locate/apenergy

[8] Cenk Sayin, Murat Ilhan, Mustafa Canakci, Metin Gumus Effect of injection timing on the exhaust emissions of a diesel engine using diesel-methanol blendsRenewable Energy 34 (2009) 1261-1269

[9] N. Ravi Kumar*, Y. M. C. Sekhar, and S. Adinarayana Effects of Compression Ratio and EGR on Performance, Combustion and Emissions of Di Injection Diesel Engine International Journal of Applied Science and Engineering 2013. 11, 1: 41-49

[10 ]Jaffar Hussain , K. Palaniradja, N. Alagumurthi, R. Manimaran Effect of Exhaust Gas Recirculation (EGR) on Performance and Emission characteristics of a Three Cylinder Direct injection Compression Ignition Engine Alexandria Engineering Journal (2012) 51, 241-247

[11] M. Ghazikhani*, M.E. Feyz, A. Joharchi Experimental investigation of the Exhaust Gas Recirculation effects on irreversibility and Brake Specific Fuel Consumption of indirect injection diesel engines Applied Thermal Engineering 30 (2010)1711-1718

[12] Giorgio Zamboni , Massimo Capobianco Experimental study on the effects of HP and LP EGR in an automotive turbocharged diesel engine Applied Energy 94 (2012) 117-128

[13] Deepak Agarwal, Shrawan Kumar Singh, Avinash Kumar Agarwal, Effect of Exhaust Gas Recirculation (EGR) on performance, emissions, deposits and durability of a constant speed compression ignition engine Applied Energy 88 (2011) 2900-2907

[14] Avinash kumar agrawal, Shrawan kumar singh, Shailendra sinha1 and Mritunjay kumar shukla, Effect of EGR on the exhaust gas temperature and exhaust opacity in compression ignition engines Sadhan a Vol. 29, Part 3, June 2004, pp. 275-284. (C) Printed in India

[15] Zhiqiang Guo, Combustion and emission characteristics of blends of diesel fuel and methanol-to-diesel, Fuel Vol. 90, 2011, pp. 1305-1308.

[16] Z.H. Zhang, Experimental investigation on regulated and unregulated emissions o f a diesel/methanol compound combustion engine with and without diesel oxidation catalyst, Science of the Total Environment, Vol. 408, 2010, pp. 865-872.

[17] Huang ZH, Lu BH, Jiang DM, Zeng K, Liu B, Wang XB, et al. Combustion characteristics and heat release analysis of a compression ignition engine operating on a Diesel/methanol blend. Proc Inst Mech Eng D: J Automob Eng 2004, Vol. 218, pp. $1011-24$.

[18] Zuohua Huang, Combustion behaviors of a compression-ignition engine fuelled with diesel/methanol blends under various fuel delivery advance angles, Bioresource Technology, Vol. 95, 2004, pp. 331-341.

[19] M.H. Mat Yasin, Characterization of a diesel engine operating with a small proportion of methanol as a fuel additive in biodiesel blend, Applied Energy, 2013.

[20] D.T. Hountalas, Effect of exhaust gas recirculation (EGR) temperature for various EGR rates on heavy duty DI diesel engine performance and emissions, Energy, Vol. 33, 2008, pp. $272-283$.

[21] Federico Millo, Analysis of different exhaust gas recirculation architectures for passenger car Diesel engines, Applied Energy, Vol. 98, 2012, pp. 79-91.

[22] Ming Zheng, Diesel engine exhaust gas recirculation a review on advanced and novel concepts, Energy Conversion and Management, Vol. 45, 2004, pp. 883-900.

[23] Harilal S. Sorathia, Effect of Exhaust Gas Recirculation (EGR) on Nox Emission from C.I. Engine, International Journal of Advanced Engineering Research and Studies, E-ISSN2249-8974.

[24] DI diesel engines", Journal of Petroleum and Gas engineering, Vol. 2(3), ISSN 2141-2677, 2011.

[25] V.Pradeep, R.P.Sharma, "Use of HOT EGR for NOx control in a compression ignition engine fuelled with biodiesel from Jatropha oil”, Renewable Energy 32 (2007) 1136-1154.

[26] H.E.Saleh, "Effect of exhaust gas recirculation on diesel engine nitrogen oxide reduction operating with jojoba methyl ester", Renewable Energy 34 (2009) 2178-2186.

[27] V.V.Pratibha Bharathi, Dr. Smt.G.Prasanthi, "Investigation on the Effect of EGR with Karanja Biodiesel and Grooved Piston with Knurling In an Internal Combustion Engine", IOSR Journal of Engineering, vol.2, issue 9, 25-31, September 2012.

[28] Suresh.R, Durgaprsad.B, SenthilKumar.P, Albert.M. "Performance analysis for emission and combustion of methanol blend diesel fuel in ci engine using glow plug". 978-1-4244-9082, 2010 IEEE. 